\title{
Improving enantioselectivity via rationally tuning electronic effects of catalysts in the organocatalytic asymmetric aldol reaction
}

\author{
Juanjuan Du, ${ }^{\text {b } Z h i y i ~ L i, ~}{ }^{\mathrm{b}}$ Da-Ming Du, ${ }^{\mathrm{b}}$ and Jiaxi $\mathrm{Xu}^{*}{ }^{*, \mathrm{ab}}$ \\ ${ }^{a}$ State Key Laboratory of Chemical Resource Engineering, and Faculty of Science, Beijing \\ University of Chemical Technology, Beijing 100029, China \\ ${ }^{b}$ Beijing National Laboratory for Molecular Sciences (BNLMS), College of Chemistry and \\ Molecular Engineering, Peking University, Beijing 100871, China
}

E-mail:jxxu@mail.buct.edu.cn

\begin{abstract}
Both steric repulsion and electronic effect govern the stereoselectivity in asymmetric catalysis. Rationally electronic-tuned $N$-(2-hydroxylphenyl)-(S)-prolinamide derived catalysts were designed, synthesized, and evaluated in the asymmetric aldol reaction. The results indicate that the enantiomeric ratios of products correlate well with the Hammett constants, which confirms that the enantioselectivity was improved via rationally tuning catalyst electronic effects.
\end{abstract}

Keywords: Asymmetric aldol reaction, electronic effect, electronic tuning, enantioselectivity, organocatalyst

\section{Introduction}

Factors governing stereoselectivity in asymmetric catalysis are important issues in organic chemistry. Asymmetric induction using optically pure catalysts has usually been interpreted as involving steric repulsion in most cases. ${ }^{1,2}$ However, enhancing the enantioselectivity by merely increasing the steric repulsion cannot always be successfully applied to every catalytic system. ${ }^{3-6}$ Recently, more and more examples indicate that the electronic effect of catalysts plays a significant role in some asymmetric catalysis. ${ }^{7-14}$ Thus, alternatively, a strategy of electronic tuning by variation of electronic character of catalysts has been explored, ${ }^{15-20}$ which offers another option for fine-tuning catalysts to improve stereoselectivity. However, so far, research on the electronic effects of catalysts on enantioselectivities has mainly concentrated on reactions catalyzed by transition metal-chiral ligand complexes; ${ }^{7-14}$ little work has concerned organocatalytic systems. ${ }^{21-28}$ 
Organocatalyzed reactions have recently enjoyed a renewed interest, and spectacular progress has been made in new catalytic methods on the basis of the use of metal-free chiral organic molecules. ${ }^{29-34}$ Proline and its analogues occupy a prominent place among the most efficient catalysts. ${ }^{35-37}$ Many act as bifunctional acid-base catalysts in transformations which include aldol, Mannich, Michael, and Diels-Alder reactions. Most reactions mediated by proline and its derivatives have similar mechanisms involving enamine intermediates and hydrogenbonding which activates electrophiles. ${ }^{35-37}$ The many explorations into enamine-based organocatalysis with proline and its derivatives began with the pioneering work of List and Barbas on the intermolecular aldol reaction. ${ }^{38}$ Since then, experimental and computational work has been reported that focused on elucidating the underlying mechanisms and factors influencing the stereoselectivities. ${ }^{39-44}$ Herein, we wish to present our results on the enantioselective improvement via rationally electronic tuning of catalysts in the prolinamide-catalyzed asymmetric aldol reaction and hope to provide some useful information in rationally tuning catalyst electronic effect to improve enantioselectivity for design and synthesis of efficient catalysts.

\section{Results and Discussion}

The generally accepted mechanism of the L-proline-catalyzed asymmetric intermolecular aldol reaction of acetone and a variety of aldehydes is illustrated in Scheme 1. ${ }^{36,37}$ Acetone and proline react to form an enamine intermediate initially. The reaction stereoselectivities have been rationalized with a Zimmerman-Traxler six-membered ring chair-like model (TS1) ${ }^{45}$ associated with the in situ formed enamine and an aldehyde. Directed and activated by the carboxylic acid group of proline, the aldehyde is attacked from its re-face to enantioselectively afford the corresponding product $\beta$-hydroxy ketone. The minor product could arise from a switch to an axial $\mathrm{R}$ group in the Zimmerman-Traxler transition state (TS2), or via the alternative Zimmerman-Traxler transition state (TS3), in which the six-membered ring transition state adopts an approximate half-chair conformation due to ring strain in two fused five-membered rings (Scheme 1). In the stereoselective controlling step, the hydrogen bonding plays a key role. A more acidic catalyst would be a better hydrogen-bond donor, and thus produce higher stereoselectivity via a tighter transition state. This idea was proved by Gong, suggesting that catalysts with electron-withdrawing groups show higher enantioselectivity than those with electron-donationg groups in the $N$-aryl and $N$-(2-hydroxylethyl)-(S)-prolinamide derivativescatalyzed aldol reaction of $p$-nitrobenzaldehyde and acetone. ${ }^{22,23}$ The same group developed an excellent catalyst for the reaction via the electronic tuning of catalysts. ${ }^{23}$ However, the reported catalysts possess some differences in stereo-structural features. ${ }^{22,23}$ After investigating rational electronic tuning of catalysts to improve enantioselectivity in the asymmetric borane reduction of ketones, ${ }^{21,24,28}$ we wished to study the correlation between the enantiomeric ratio of product and the Hammett constant of the catalyst substituent in the asymmetric aldol reaction system, to 
understand the electronic tuning by using the designed catalysts with very similar structural feature to completely exclude steric difference. $N$-(2-Hydroxylphenyl)- $(S)$-prolinamide was shown to catalyze the asymmetric aldol reaction with low enantioselectivity. ${ }^{46}$ It possesses two hydrogen-bond donors (an amide $\mathrm{H}$ and a phenolic hydroxy $\mathrm{H}$ ) and should catalyze the asymmetric aldol reaction via a favorable transition state (TS4, Scheme 1), similar to that in the $N$-(2-hydroxylethyl)-(S)-prolinamide derivatives-catalyzed reaction suggested by Gong, et al. ${ }^{23}$ To study the enantioselective improvement via rationally tuning the electronic effect of catalysts specifically, we designed a series of catalysts 1a-d. By varying the substituent $R$ on the phenyl moiety, the strength of the hydrogen-bond can be easily tuned without significant change of the steric situation.

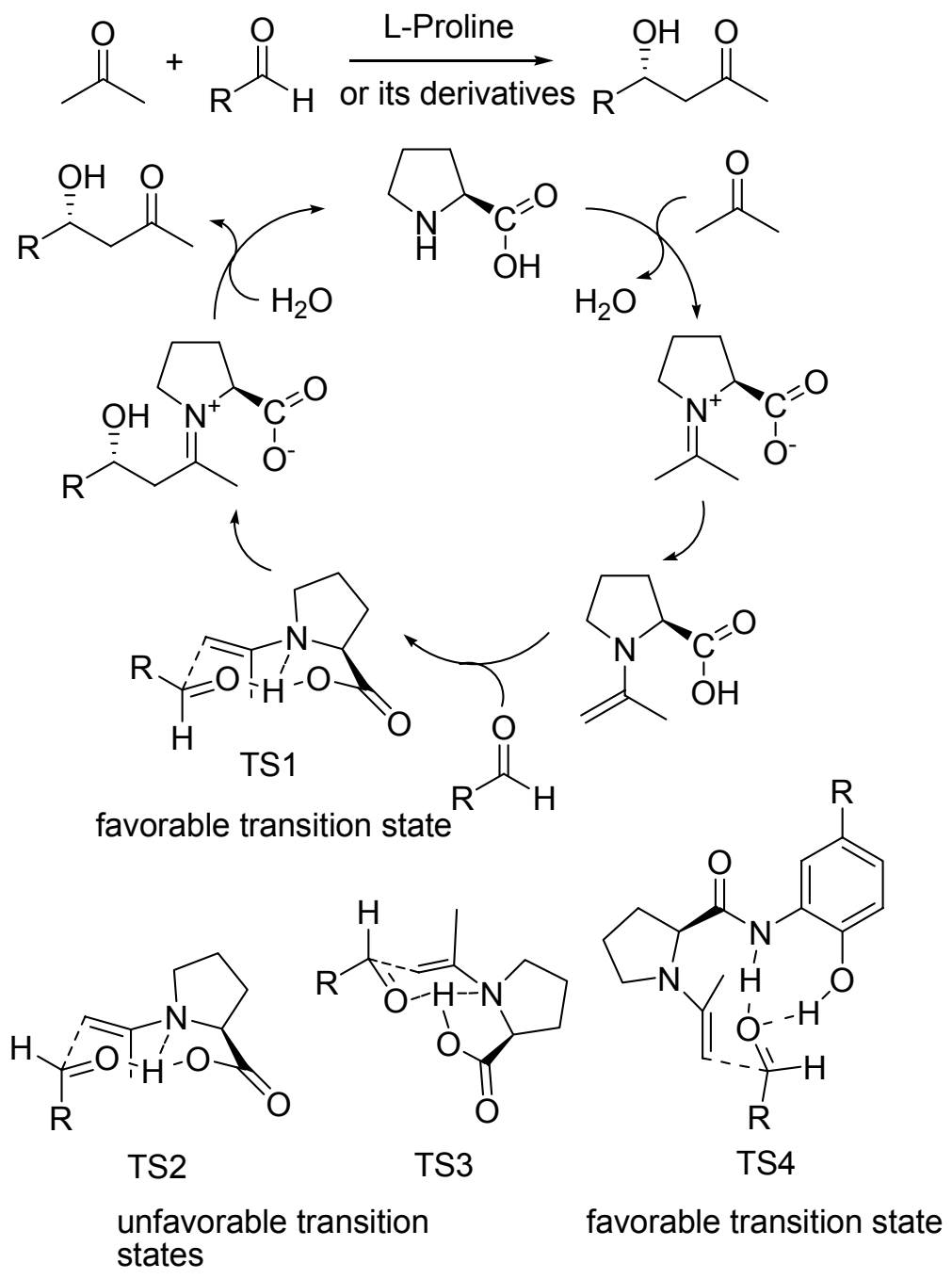

Scheme 1. Mechanism and transition states in the asymmetric direct aldol reaction catalyzed by (S)-proline and $N$-(2-hydroxylphenyl)-(S)-prolinamide derived catalysts. 
The modular nature of the catalysts $\mathbf{1}$ makes them well-suited for the investigation, as catalysts 1 can be rapidly synthesized and evaluated to probe the relationship between the electronic effect and activity of catalysts. The catalysts 1a-c were prepared from $N$-Cbz protected proline and the corresponding $o$-aminophenols in two steps with satisfactory yields according to the literature method. ${ }^{46}$ Considering that a nitro group would be easily reduced in a reductive deprotection step, the catalyst 1d was synthesized from $N$-Boc protected proline and 2-amino-4nitrophenol (Scheme 2).<smiles>[R]c1ccc(O)c(NC(=O)[C@@H]2CCCN2)c1</smiles>

2a-c

a: $\mathrm{R}=\mathrm{Me}, \mathbf{b}: \mathrm{R}=\mathrm{H}, \mathbf{c}: \mathrm{R}=\mathrm{Cl}$<smiles>Nc1cc(C(=O)Nc2cc(O)c(NC(=O)[C@@H]3CCCN3C(=O)[OH2+])cc2[N+](=O)[O-])cc([N+](=O)[O-])c1</smiles>

Scheme 2. Synthesis of $N$-(2-hydroxylphenyl)-(S)-prolinamide derived catalysts 1 
Table 1. Asymmetric direct aldol reaction of acetone and 4-nitrobenzaldehyde catalyzed by $N$-(2-hydroxylphenyl)-(S)-prolinamide derived catalysts 1a-d.

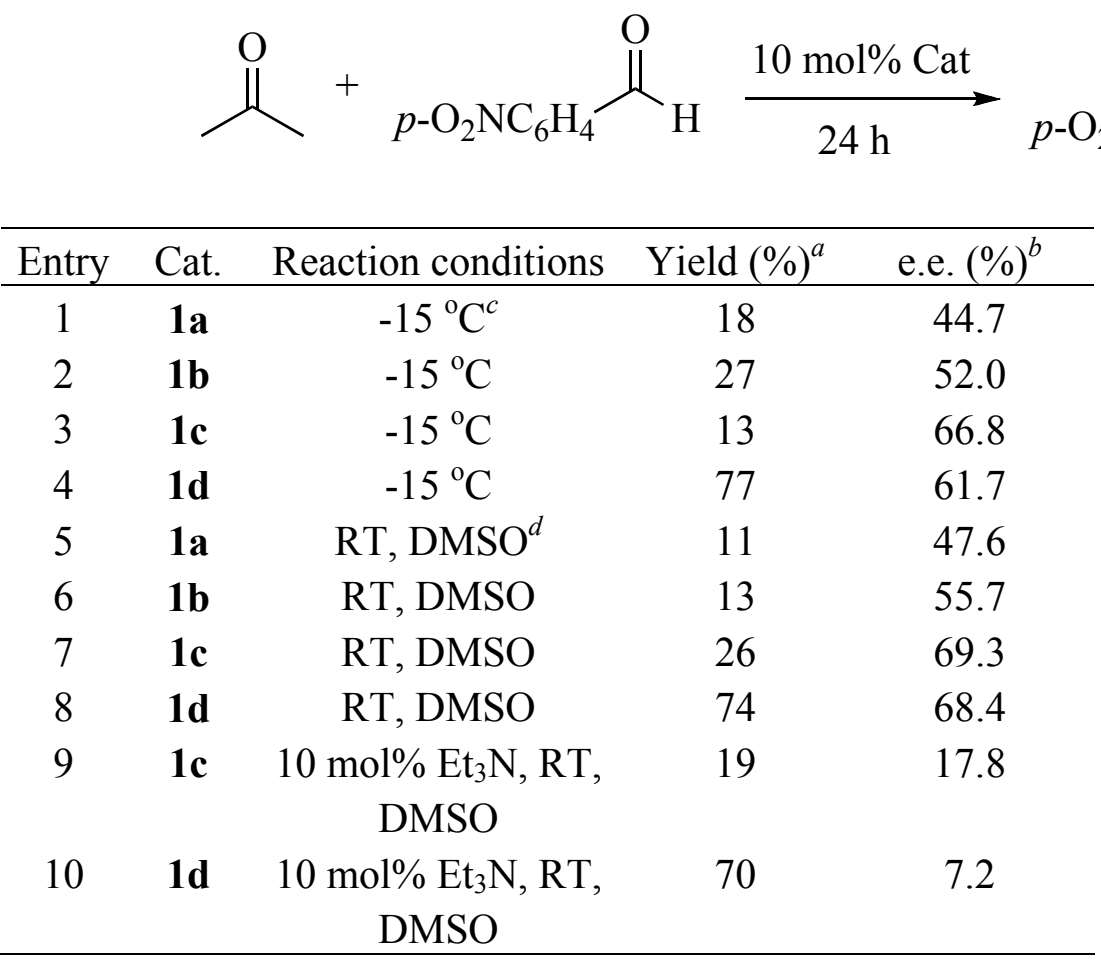

${ }^{a}$ Isolated yield. ${ }^{b}$ Determined by chiral HPLC analysis and the configuration of major enantiomeric product was identified as $R$ by comparison of retention times with authentic samples. ${ }^{c}$ Conducted without solvent. ${ }^{d}$ Conducted with $p$-nitrobenzaldehyde $(1 \mathrm{mmol})$, acetone $(5 \mathrm{mmol})$, and catalyst $(0.1 \mathrm{mmol})$ in $0.3 \mathrm{~mL}$ of DMSO.

With the catalysts in hand, we tested the reaction of acetone and 4-nitrobenzaldehyde under solvent-free condition with the catalysts 1a-d after optimizing reaction conditions (data not shown). As shown in Table 1 (entries 1-4), the electronic nature of the substituent clearly affected the yield and enantioselectivity. Catalysts 1c and 1d with electron-withdrawing groups had better catalytic performance in enantioselectivity (Table 1, entries 3 and 4), whereas catalyst 1a with an electron-donating methyl group gave the lowest ee value (Table 1, entry 1).

To further analyze the electronic effect observed in the asymmetric aldol reaction, the correlations of $\ln ([\mathrm{R}] /[\mathrm{S}])$ with Hammett constants of both para-substituents $\left(\sigma_{\text {para }}\right)$ and metasubstituents $\left(\sigma_{\text {meta }}\right)$ were conducted using the Hammett equation $\ln ([\mathrm{R}] /[\mathrm{S}])=\rho \sigma+c{ }^{47}$ As shown in Figure 1 [lines for acetone (para) and acetone (meta)], enantiomeric ratio $(\ln ([\mathrm{R}] /[\mathrm{S}]))$ correlates very well with both para and meta Hammett constants $\left(\sigma_{\text {para }}\right.$ and $\left.\sigma_{\text {meta }}\right)$ with $\rho=1.73$ and $1.42, R^{2}=0.993$ and 0.975 , respectively, if only the data of catalyst 1a-c were taken into consideration. The data points obtained from the reaction catalyzed by $\mathbf{1 d}$ are outliers. We did not include them in the Hammett analysis. The detailed explanations for the omission will be discussed (vide infra). 


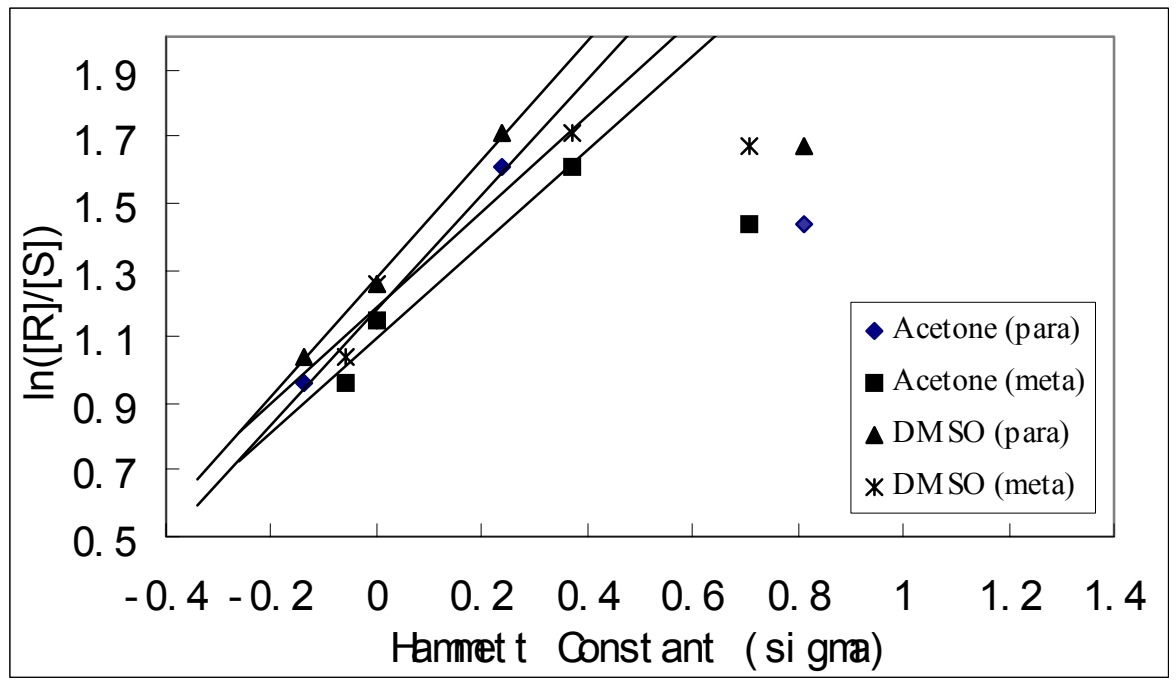

Figure 1. Hammett plots in the asymmetric direct aldol reaction catalyzed by $N-(2-$ hydroxylphenyl) (S)-prolinamide derived catalysts.

Possible reasons for the low e.e. value in the reaction catalyzed by $\mathbf{1 d}$ is that its solubility is much lower than its analogues or that its acidity is too strong to increase the rate of free acidcatalyzed aldol reaction (non-asymmetric reaction caused by proton dissociated from catalyst 1d). We found that 1d does not dissolve completely in the reaction system with $10 \%$ catalyst loading, unlike the other three. The amount of efficient catalyst was probably lower than $10 \%$ in the catalyst 1d-catalyzed reaction. To eliminate the influence of the different solubilities of catalysts on enantioselecitivties, similar reactions were conducted in DMSO after optimizing reaction conditions (data not shown) (Table 1, entries 5-8). Although all the catalysts dissolved in DMSO, the experimental results changed little. As shown in Table 1 (entries 5-8) and Figure 1 [lines for DMSO (para) and DMSO (meta)], $\ln ([\mathrm{R}] /[\mathrm{S}])$ demonstrated good correlations with both $\sigma_{\text {para }}$ and $\sigma_{\text {meta }}$ with $\rho=1.78$ and $1.44, R^{2}=0.998$ and 0.961 , respectively, if only the data of catalyst 1a-c were taken into consideration. The results indicate that the low solubility is not the reason for the lower stereoselectivity of catalyst $\mathbf{1 d}$.

The positive slopes of the Hammett plots are in good agreement with the assumption and earlier reported results. ${ }^{22,23}$ That is, the hydrogen-bonding interaction between the catalyst and the aldehyde is crucial to the catalytic activity and stereoselectivity. In the electron-withdrawing group of catalysts, the acidities of both the hydrogen atoms in the amide moiety and the hydroxyl group are greater, and consequently enhance the strength and shorten the length of the hydrogen bond. Therefore, the transition state would be tighter, which results in better enantioselectivity. Hammett analyses indicate that the catalytic asymmetric aldol reaction shows a similar influence of the electronic effect of catalysts on the enantioselectivity in acetone and in DMSO, and also indicate that the para-substituents show a greater effect than the meta-substituents in both reaction systems. 
As the acidity of the catalysts increase, the ee values first increase, but then decrease. The ee values observed with catalyst 1d did not follow the expected increasing trend. What is the factor causing the low ee values with catalyst 1d? We suspect that the strong electron-withdrawing nitro group facilitates the dissociation of the hydrogen of the phenolic hydroxyl, resulting in a decreased number of effective hydrogen bonds. Hence, the aldehyde is not bound as tightlky as it is in the reactions catalyzed by catalyst 1c, and the enantioselectivity thus decreases. To support this supposition, we added $10 \mathrm{~mol}_{\%}$ of $\mathrm{NEt}_{3}$ to the reactions catalyzed by $\mathbf{1 c}$ and $\mathbf{1 d}$ to remove their phenolic hydroxyl hydrogen-bond donor. The ee values dropped dramatically from $69.3 \%$ to $17.8 \%$ for $1 \mathrm{c}$ and from $68.4 \%$ to $7.2 \%$ for $\mathbf{1 d}$, respectively, validating our assumption (Table 1, entries 7 and 9, 8 and 10). In addition, the proton released from the hydroxyl group could probably serve as an acidic catalyst for the background, racemic reaction. This also causes a decrease in the enantioselectivity. The results show that the nitro group, which is the strongest electron-withdrawing group among the neutral substituents, is too strong an electronwithdrawing group to enhance the enantioselectivity of catalyst $\mathbf{1 b}$ and goes beyond the rationally tuning scope. The results also indicate that the electronic nature of catalysts can only be fine-tuned.

To investigate the influence of the electronic effect of catalysts on diastereoselectivity in the asymmetric aldol reaction, we also carried out the reaction of cyclohexanone and 4nitrobenzaldehyde (Table 2, entries 1-4). The results indicate that catalysts with electronwithdrawing groups show higher diastereoselectivity and enantioselectivity than those with electron-donating groups. Our catalysts 1a-d show similar asymmetric catalytic process to Lproline, ${ }^{38}$ giving the anti-isomer as a major product.

Table 2. Asymmetric direct aldol reaction of cycloalkanones and 4-nitrobenzaldehyde catalyzed by $N$-(2-hydroxylphenyl)-(S)-prolinamide derived catalysts $\mathbf{1 a - d .}$

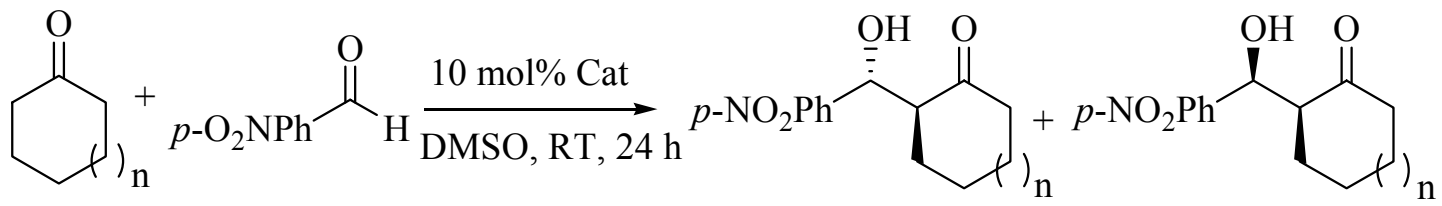

anti

\begin{tabular}{rcccccc}
\hline Entry & Cat. & n & ${\text { Yield }(\%)^{a}}^{a}$ & ${\text { Anti: }: s y n^{b}}^{b}$ & e.e. $(\%)(a n t i)^{c}$ & e.e. $(\%)(s y n)^{d}$ \\
\hline 1 & 1a & 1 & 61 & $63: 37$ & 47.7 & 28.0 \\
2 & 1b & 1 & 40 & $67: 33$ & 58.4 & 38.7 \\
3 & 1c & 1 & 55 & $80: 20$ & 63.9 & 42.9 \\
4 & 1d & 1 & 40 & $72: 28$ & 73.3 & 44.3 \\
5 & 1d & 0 & 55 & $74: 26$ & 71.3 & 68.9 \\
\hline
\end{tabular}

${ }^{a}$ Isolated yield. ${ }^{b}$ Determined by ${ }^{1} \mathrm{H}$ NMR and confirmed by chiral HPLC analysis. ${ }^{c}$ Determined by chiral HPLC analysis and the configuration of major enantiomeric product was identified as $\left(2 S, 1^{\prime} R\right)$ by comparison of retention times with authentic samples. ${ }^{d}$ Determined by chiral HPLC 
analysis and the configuration of major enantiomeric product was identified as $(2 S, 1 ' S)$ by comparison of retention times with authentic samples.

Reactions of cyclopentanone and butanone with 4-nitrobenzaldehyde were also conducted using catalyst 1d. Cyclopentanone also gave rise to the anti-isomer as a major product with diastereoselectivity and enantioselectivity similar to that with cyclohexanone, but showed better enantioselectivity for the syn-isiomer than with cyclohexanone (Table 2, entry 5). Butanone reacted at its methyl group to afford the $R$ product as a majority in a low yield of $4.8 \%$ with a moderate enantioselectivity ( $64 \%$ ee)

All results indicate that our catalysts 1a-d show the same diastereofacial and enantiofacial selectivities as Gong's $N$-(2-hydroxylethyl)-(S)-prolinamide derived catalysts. ${ }^{23}$ This supports our assumption of a transition state (TS4) in our asymmetric catalysis.

In summary, rationally electronic effect tuned $N$-(2-hydroxylphenyl)-(S)-prolinamide derived catalysts were designed, synthesized, and evaluated in the asymmetric aldol reaction. The results indicate that catalysts with electron-withdrawing groups show higher diastereoselectivity and enantioselectivity than those with electron-donating groups and the enantiomeric ratios of products correlate very well with both para and meta Hammett constants, which confirms that the enantioselectivity was really improved via rationally tuning catalyst electronic effect, but only fine-tuned in a suitable range. Our results provide some useful information for designing efficient catalysts via considering rationally fine-tuning catalyst electronic effect.

\section{Experimental Section}

General Procedures. Melting points were measured on a Yanaco MP-500 melting point apparatus and are uncorrected. ${ }^{1} \mathrm{H}$ NMR and ${ }^{13} \mathrm{C}$ NMR spectra were recorded on a Varian Mercury $200(200 \mathrm{MHz})$, or a Varian Mercury Plus $300(300 \mathrm{MHz})$ spectrometer in $\mathrm{CDCl}_{3}$ with TMS as an internal standard or in $\left[\mathrm{d}_{6}\right]$ DMSO. Mass spectra were obtained on a Brucker ESQUIRE $\sim$ LC ${ }^{\mathrm{TM}}$ ESI ion trap mass spectrometer. HRMS data was carried out on an Agilent LC/MSD TOF mass spectrometer. IR spectra were determined on a Nicolet AVATAR 330 FTIR spectrometer. CHN analyses were recorded on an Elementar Vario EL analyzer. Optical rotations were measured on a Perkin Elmer Model 341LC polarimeter with a thermally jacketed $10 \mathrm{~cm}$ cell (concentration $c$ expressed as $\mathrm{g} / 100 \mathrm{~mL}$ ). HPLC analyses were performed with Agilent HP1100 HPLC equipment. The ee values were determined by HPLC analysis with chiral columns $(4.6 \times 250 \mathrm{~mm})$ applying a mixture of hexane-isopropanol as an eluent and monitoring wavelength of $254 \mathrm{~nm}$.

\section{General procedure for the preparation of catalysts (1a-c)}

To a stirred solution of $N$-benzyloxycarbonyl-L-proline $(1.25 \mathrm{~g}, 5.00 \mathrm{mmol})$ in $\mathrm{CH}_{2} \mathrm{Cl}_{2}(20 \mathrm{~mL})$ was added 2-aminophenol or its derivative $(5 \mathrm{mmol})$ in $\mathrm{CH}_{2} \mathrm{Cl}_{2} \quad(10 \mathrm{~mL})$. 4- 
(Dimethylamino)pyridine (DMAP, $61 \mathrm{mg}, 0.5 \mathrm{mmol}$ ) and 1,3-dicyclohexylcarbodiimide (DCC $1.03 \mathrm{~g}, 5 \mathrm{mmol}$ ) dissolved in $10 \mathrm{~mL}$ of $\mathrm{CH}_{2} \mathrm{Cl}_{2}$ were added to the resulting mixture. After stirring at room temperature for $20 \mathrm{~h}$, the mixture was filtered. The resulting solution was washed with $1 \mathrm{~mol} / \mathrm{L} \mathrm{HCl}$, water, saturated $\mathrm{NaHCO}_{3}$, then brine. After drying over sodium sulfate, the solution was concentrated under reduced pressure to afford a pale yellow oil.

Without further purification, the oil, $10 \% \mathrm{Pd} / \mathrm{C}(0.269 \mathrm{~g})$ and methanol $(30 \mathrm{~mL})$ were placed in a round-bottom flask and stirred under a hydrogen atmosphere at room temperature for $8 \mathrm{~h}$. After filtration through Celite to remove the solids, the solution was evaporated to dryness. The resulting oil was purified on a silica gel column with a mixture of chloroform and methanol (9:1, $\mathrm{v} / \mathrm{v}$ ) to give the corresponding product $\mathbf{1}$ which was further purified by recrystallization from a mixture of methanol and diethyl ether.

$\mathrm{N}$-(2-Hydroxy-5-methylphenyl)-(S)-pyrrolidine-2-carboxamide (1a). Overall yield 65\%; colorless crystals; m.p. $162-163{ }^{\circ} \mathrm{C} ;[\alpha]^{20}{ }_{\mathrm{D}}=-58.4\left(c\right.$ 0.9, $\left.\mathrm{CH}_{3} \mathrm{OH}\right) ;{ }^{1} \mathrm{H}$ NMR $\left(300 \mathrm{MHz}, \mathrm{CDCl}_{3}\right)$ $\delta 1.77$ (quintet, $J=6.6 \mathrm{~Hz}, 2 \mathrm{H}), 1.98-2.08(\mathrm{~m}, 1 \mathrm{H}), 2.16-2.29(\mathrm{~m}, 1 \mathrm{H}), 2.24(\mathrm{~s}, 3 \mathrm{H}), 2.96-3.14$ $(\mathrm{m}, 2 \mathrm{H}), 2.93(\mathrm{dd}, J=5.1,9.3 \mathrm{~Hz}, 1 \mathrm{H}), 6.79(\mathrm{~s}, 1 \mathrm{H}), 6.89(\mathrm{~s}, 2 \mathrm{H}) 9.92(\mathrm{~s}, \mathrm{br}, 2 \mathrm{H}) .{ }^{13} \mathrm{C}$ NMR $(75$ $\left.\mathrm{MHz}, \mathrm{CDCl}_{3}\right) \delta 20.2,26.2,30.8,47.3,60.2,119.5,122.3,124.6,127.6,129.4,146.6,175.0$. IR (neat), $v\left(\mathrm{~cm}^{-1}\right): 3027$ (br), 2757, 1680, 1548, 1508, 1457, 1380, 1349, 1281, 1209, 815; MS (ESI) $m / z: 221[\mathrm{M}+\mathrm{H}]^{+}$. Anal. Calcd for $\mathrm{C}_{12} \mathrm{H}_{16} \mathrm{~N}_{2} \mathrm{O}_{2}$ : C, 65.43; H, 7.32; N, 12.72\%. Found: C, $65.43 ; \mathrm{H}, 7.32 ; \mathrm{N}, 12.75 \%$.

$\boldsymbol{N}$-(2-Hydroxyphenyl)-(S)-pyrrolidine-2-carboxamide (1b). Overall yield 50\%; colorless crystals; m.p. $170-172{ }^{\circ} \mathrm{C} ;[\alpha]^{20}{ }_{\mathrm{D}}=-47.7$ (c 1.0, $\left.\mathrm{CH}_{3} \mathrm{OH}\right) ;{ }^{1} \mathrm{H}$ NMR $\left(300 \mathrm{MHz}, \mathrm{CDCl}_{3}\right) \delta 1.79$ (quintet, $J=6.6 \mathrm{~Hz}, 2 \mathrm{H}), 1.99-2.10(\mathrm{~m}, 1 \mathrm{H}), 2.18-2.32(\mathrm{~m}, 1 \mathrm{H}), 2.98-3.16(\mathrm{~m}, 2 \mathrm{H}), 3.97(\mathrm{dd}, 1 \mathrm{H}$, $J=5.1,9.3 \mathrm{~Hz}), 6.81-6.87(\mathrm{~m}, 1 \mathrm{H}), 6.94-7.03(\mathrm{~m}, 2 \mathrm{H}), 7.08-7.14(\mathrm{~m}, 1 \mathrm{H}), 9.99(\mathrm{~s}, \mathrm{br}, 2 \mathrm{H}) .{ }^{13} \mathrm{C}$ NMR $\left(75 \mathrm{MHz}, \mathrm{CDCl}_{3}\right) \delta 26.2,30.9,47.3,60.2,119.9,120.0,122.1,125.0,127.1,149.1,175.0$. IR (neat), $v\left(\mathrm{~cm}^{-1}\right): 3034$ (br), 1680, 1542, 1457, 1284, 753; MS (ESI) m/z: $207[\mathrm{M}+\mathrm{H}]^{+}$. HRMS (ESI): Anal. Calcd for $\mathrm{C}_{11} \mathrm{H}_{15} \mathrm{~N}_{2} \mathrm{O}_{2}[\mathrm{M}+\mathrm{H}]^{+}:$207.1128, found 207.1131.

$\boldsymbol{N}$-(5-Chloro-2-hydroxyphenyl)-(S)-pyrrolidine-2-carboxamide (1c). Overall yield 59\%; white solid; m.p. $186-190{ }^{\circ} \mathrm{C}$, sensitive in air/light. $[\alpha]^{20}{ }_{\mathrm{D}}=-60.3^{48}\left(c 0.7, \mathrm{CH}_{3} \mathrm{OH}\right)$; ${ }^{1} \mathrm{H}$ NMR $\left(200 \mathrm{MHz}, \mathrm{CDCl}_{3}\right) \delta 1.72-1.86(\mathrm{~m}, 2 \mathrm{H}), 1.96-1.12(\mathrm{~m}, 1 \mathrm{H}), 2.17-2.35(\mathrm{~m}, 1 \mathrm{H}), 2.96-3.19(\mathrm{~m}$, 2H), $3.95(\mathrm{dd}, 1 \mathrm{H}, J=4.2,5.2 \mathrm{~Hz}), 5.45(\mathrm{~s}, \mathrm{br}, 1 \mathrm{H}), 6.80-7.28(\mathrm{~m}, 3 \mathrm{H}), 9.97(\mathrm{~s}, \mathrm{br}, 2 \mathrm{H}) .{ }^{13} \mathrm{C} \mathrm{NMR}$ (75 MHz, [d $\mathrm{d}_{6}$ ]DMSO) $\delta$ 24.1, 30.1, 45.9, 59.6, 116.5, 121.0, 122.0, 124.3, 126.7, 146.9, 168.7. IR (neat, $\mathrm{cm}^{-1}$ ) 2950 (br), 1677, 1531, 1424, 1269, 1117, 1026, 813; MS (ESI) m/z: $241[\mathrm{M}+\mathrm{H}]^{+}$. HRMS (ESI): Anal. Calcd for $\mathrm{C}_{11} \mathrm{H}_{14} \mathrm{~N}_{2} \mathrm{ClO}_{2}[\mathrm{M}+\mathrm{H}]^{+}$: 241.0738, found 241.0744.

\section{General procedure for the preparation of catalyst (1d)}

$N$-(tert-Butoxycarbonyl)-L-proline (1.075 g, $5 \mathrm{mmol})$ and DCC (1.13 g, $5.5 \mathrm{mmol})$ were dissolved in $15 \mathrm{~mL}$ of dried THF. After stirring at room temperature for $30 \mathrm{~min}$, 2-amino-5nitrophenol $(0.77 \mathrm{~g}, 5 \mathrm{mmol})$ was added. After stirring overnight, the solvent was removed under reduced pressure, the resulting solid was purified through a silica gel column with an eluent of $\mathrm{CH}_{2} \mathrm{Cl}_{2}$ and $\mathrm{CH}_{3} \mathrm{OH}(50: 1, \mathrm{v} / \mathrm{v})$ to afford a light yellow solid $\mathbf{2 d}$. 
To a stirred ice-cooled solution of $2 \mathrm{~d}(0.526 \mathrm{~g}, 1.5 \mathrm{mmol})$ in $30 \mathrm{~mL}$ of $\mathrm{CH}_{2} \mathrm{Cl}_{2}$ was added $5 \mathrm{~mL}$ of TFA dropwise. The reaction was allowed to warm up to room temperature and monitored with TLC. After 1d was consumed completely, the solution was evaporated under reduced pressure. The resulting residue was dissolved in $40 \mathrm{~mL}$ of water. The aqueous solution was neutralized to pH 7-8 with $0.5 \mathrm{~mol} / \mathrm{L} \mathrm{NaOH}$ to give a precipitate of compound $\mathbf{1 d}$.

$\boldsymbol{N}$-(2-Hydroxy-5-nitrophenyl)-(S)-pyrrolidine-2-carboxamide (1d). Overall yield 42\%; yellow solid; m.p. $230{ }^{\circ} \mathrm{C}$ (dec.). $[\alpha]^{20}{ }_{\mathrm{D}}=-74.9$ (c 0.4, DMSO); ${ }^{1} \mathrm{H}$ NMR (300 MHz, DMSO- $\left.d_{6}\right) \delta 1.70-$ $1.79(\mathrm{~m}, 2 \mathrm{H}), 1.80-1.90(\mathrm{~m}, 1 \mathrm{H}), 2.12-2.23(\mathrm{~m}, 1 \mathrm{H}), 2.96-3.12(\mathrm{~m}, 2 \mathrm{H}), 4.32(\mathrm{dd}, J=6.3,8.1 \mathrm{~Hz}$, $1 \mathrm{H}), 4.31(\mathrm{~s}, \mathrm{br}, 2 \mathrm{H}), 6.68(\mathrm{~d}, J=9.0 \mathrm{~Hz}, 1 \mathrm{H}), 7.82(\mathrm{dd}, J=2.3,9.0 \mathrm{~Hz}, 1 \mathrm{H}) 9.01(\mathrm{~d}, J=2.3 \mathrm{~Hz}$, $1 \mathrm{H}) .{ }^{13} \mathrm{C}$ NMR $\left(75 \mathrm{MHz}, \mathrm{DMSO}-d_{6}\right) \delta 25.0,30.1,46.4,60.4,114.0,114.8,121.9,127.0,134.6$, 160.4, 170.9. IR (neat), $v\left(\mathrm{~cm}^{-1}\right): 3150$ (br), 1662, 1578, 1538, 1481, 1265, 1243, 1076; MS (ESI) $\mathrm{m} / \mathrm{z}: 252[\mathrm{M}+\mathrm{H}]^{+}$. HRMS (ESI): Anal. Calcd for $\mathrm{C}_{11} \mathrm{H}_{14} \mathrm{~N}_{3} \mathrm{O}_{4}[\mathrm{M}+\mathrm{H}]^{+}$: 252.0979, found 252.0978 .

\section{General procedure for the asymmetric aldol reaction}

To a solution of a ketone $(5 \mathrm{mmol})$ in a solvent $(0.3 \mathrm{~mL})$ was added a catalyst $1(0.1 \mathrm{mmol})$. The mixture was stirred at room temperature for $15 \mathrm{~min}$, and then 4-nitrobenzaldehyde $(0.151 \mathrm{~g}$, $1 \mathrm{mmol}$ ) was added. The resulting mixture was stirred at the desired temperature for $24 \mathrm{~h}$. The reaction mixture was treated with saturated ammonium chloride solution $(20 \mathrm{~mL})$. The layers were separated, and the aqueous layer was extracted with ethyl acetate $(3 \times 20 \mathrm{~mL})$. The combined organic layers were washed with brine and dried over anhydrous sodium sulfate. After removal of solvent, the residue was purified through flash column chromatography on a silica gel with hexanes-ethyl acetate $(2: 1, \mathrm{v} / \mathrm{v})$ to afford the pure adducts. The enantiomeric excess value was determined by HPLC on an AS, AD, or OJ-H column.

4-Hydroxy-4-(4-nitrophenyl)butan-2-one. Enantiomeric excess was determined by HPLC (Daicel Chiralpak AS, $i-\mathrm{PrOH} /$ hexane $=30 / 70, \mathrm{v} / \mathrm{v}$ ) at flow rate $1.0 \mathrm{~mL} / \mathrm{min}$.with $R$-isomer $t_{R}$ $21.6 \mathrm{~min}$ and $S$-isomer $t_{R} 29.9 \mathrm{~min}$.

2-[Hydroxy-(4-nitrophenyl)methyl]cyclohexanone. Enantiomeric excess was determined by HPLC (Daicel Chiralpak AD, $i-\mathrm{PrOH} /$ hexane $=20 / 80, \mathrm{v} / \mathrm{v}$ ) at flow rate $0.6 \mathrm{~mL} / \mathrm{min}$. with $t_{R}$ $\left(2 R, 1^{\prime} R\right) 18.4$ min., $t_{R}\left(2 S, 1^{\prime} S\right) 21.7$ min., $t_{R}\left(2 R, 1^{\prime} S\right) 23.5 \mathrm{~min}$., and $t_{R}\left(2 S, 1^{\prime} R\right) 30.1 \mathrm{~min}$.

2-[Hydroxy-(4-nitrophenyl)methyl]cyclopentanone. Enantiomeric excess was determined by HPLC (Daicel Chiralpak AD, $i-\mathrm{PrOH} /$ hexane $=10 / 90, \mathrm{v} / \mathrm{v}$ ) at flow rate $1.0 \mathrm{~mL} / \mathrm{min}$. with $t_{R}$ $\left(2 R, 1^{\prime} R\right) 14.7 \mathrm{~min} ., t_{R}\left(2 S, 1^{\prime} S\right) 19.1 \mathrm{~min} ., t_{R}\left(2 R, 1^{\prime} S\right) 25.2 \mathrm{~min}$, and $t_{R}\left(2 S, 1^{\prime} R\right) 26.4 \mathrm{~min}$.

1-Hydroxy-1-(4-nitrophenyl)pentan-3-one. Enantiomeric excess was determined by HPLC (Daicel Chiralpak OJ-H, $i$-PrOH$/$ hexane $=22 / 78, \mathrm{v} / \mathrm{v}$ ) at flow rate $0.8 \mathrm{~mL} / \mathrm{min}$. with $R$-isomer $t_{R}$ $15.8 \mathrm{~min}$ and $S$-isomer $t_{R} 17.2 \mathrm{~min}$. 


\section{Acknowledgements}

This work was supported in part by the National Natural Science Foundation of China (Project Nos. 20272002 and 20472005) and the "Chun-Tsung Chinese Undergraduate Research Endowment".

\section{References}

1. Ojima, I. Catalytic Asymmetric Synthesis 2nd Ed., John Wiley: New York, 2004.

2. Noyori, R. Asymmetric Catalysis in Organic Synthesis, John Wiley, New York, 1994.

3. Ma, L. G.; Jiao, P.; Zhang, Q. H.; Du, D. M.; Xu, J. X. Tetrahedron: Asymmetry 2005, 16, 3718.

4. Ma, L. G.; Du, D. M.; Xu, J. X. J. Org. Chem. 2005, 70, 10155.

5. Xu, J. X.; Ma, L. G.; Jiao, P. Chem. Commun. 2004, 1616.

6. Jiao, P.; Xu, J. X.; Zhang, Q. H.; Choi, C. M.; Chan, A. S. C. Tetrahedron: Asymmetry, 2001, 12, 3081.

7. Tu, T.; Hou, X. L.; Dai, L. X. J. Organomet. Chem. 2004, 689, 3847.

8. Fu, Y.; Hou, G. H.; Xie, J. H.; Xing, L.; Wang, L. X.; Zhou, Q. L. J. Org. Chem. 2004, 69, 8157.

9. Jeulin, S.; De Paule, S. D.; Ratovelomanana-Vidal, V.; Genet, J. P.; Champion, N.; Dellis, P. Proc. Natl. Acad. Sci. USA 2004, 101, 5799.

10. Cavallo, L.; Jacobsen, H. J. Org. Chem. 2003, 68, 6202.

11. Jew, S. S.; Yoo, M. S.; Jeong, B. S.; Park, I. Y.; Park, H. G. Org. Lett. 2002, 4, 4245.

12. Ma, L. G.; Jiao, P.; Zhang, Q. H.; Du, D. M.; Xu, J. X. Tetrahedron: Asymmetry 2007, 18, 878.

13. Nelson, D. W.; Gypser, A.; Ho, P. T.; Kolb, H. C.; Kondo, T.; Kwong, H. L.; McGrath, D. V.; Rubin, A. E.; Norrby, P. O.; Gable, K. P.; Sharpless, K. B. J. Am. Chem. Soc. 1997, 119, 1840.

14. Nakagawa, H.; Sei, Y.; Yamaguchi, K.; Nagano, T.; Higuchi, T. Tetrahedron: Asymmetry 2004, 15, 3861.

15. For a recent review, see: Flanangan, S. P.; Guiry, P. J. J. Organomet. Chem. 2006, 691, 2125.

16. Jacobsen, E. N.; Zhang, W.; Güler, M. L. J. Am. Chem. Soc. 1991, 113, 6703.

17. Palucki, M.; Finney, N. S.; Pospisil, P. J.; Güler, M. L.; Ishida, T.; Jacobsen, E. N. J. Am. Chem. Soc. 1998, 120, 948.

18. Busacca, C. A.; Grossbach, D.; So, R. C.; O'Brien, E. M.; Spinelli, E. M. Org. Lett. 2003, 5, 595.

19. Nakagawa, H.; Sei, Y.; Yamaguchi, K.; Nagano, T.; Higuchi, T. Tetrahedron: Asymmetry 2004, 15, 3861.

20. List, B.; Pojarliev, P.; Biller, W. T.; Martin, H. J. J. Am. Chem. Soc. 2002, 124, 827. 
21. Xu, J. X.; Wei, T. Z.; Zhang, Q. H. J. Org. Chem. 2004, 69, 6860.

22. Tang, Z.; Jiang, F.; Cui, X.; Gong, L. Z.; Mi, A. Q.; Jiang, Y. Z.; Wu, Y. D. Proc. Natl. Acad. Sci. USA 2004, 101, 5755.

23. Tang, Z.; Yang, Z. H.; Chen, X. H.; Cun, L. F.; Mi, A. Q.; Jiang, Y. Z.; Gong, L. Z. J. Am. Chem. Soc. 2005, 127, 9285.

24. Liu, H.; Xu, J. X. J. Mol. Cat. A: Chem. 2006, 244, 68.

25. Chen, W.; Yuan, X. H.; Li, R.; Du, W.; Wu, Y.; Ding, L. S.; Chen, Y. C. Adv. Synth. Catal. 2006, 348, 1818.

26. Tozawa, T.; Nagao, H.; Yamane, Y.; Mukaiyama, T. Chem. Asian J. 2007, 2, 123.

27. Jensen, K. H.; Sigman, M. S. Angew. Chem. Int. Ed. 2007, 46, 4748.

28. Du, J. J.; Li, Z. Y.; Du, D. M.; Xu, J. X. J. Mol. Cat. A: Chem. 2008, 284, 40.

29. For recent reviews, see: Dalko, P. I.; Moisan, L. Angew. Chem. Int. Ed. 2004, 43, 5138.

30. Seayad, J.; List, B. Org. Biomol. Chem. 2005, 3, 719.

31. Dalko, P. I.; Moisan, L. Angew. Chem. Int. Ed. 2001, 40, 3726.

32. Taylor, M. S.; Jacobsen, E. N. Angew. Chem. Int. Ed. 2006, 45, 1520.

33. Schreiner, P. R. Chem. Soc. Rev. 2003, 32, 289.

34. Akiyama, T.; Itoh, J.; Fuchibe, K. Adv. Synth. Catal. 2006, 348, 999.

35. For recent reviews, see: List, B. Tetrahedron 2002, 58, 5573.

36. Notz, W.; Tanaka, F.; Barbas C. F. III. Acc. Chem. Res. 2004, 37, 558.

37. List, B. Acc. Chem. Res. 2004, 37, 548.

38. List, B.; Lerner, R. A.; Barbas, C. F. III. J. Am. Chem. Soc. 2000, 122, 2395.

39. List, B.; Hoang, L.; Martin, H. J. Proc. Natl. Acad. Sci. USA 2004, 101, 5839.

40. Hoang, L.; Bahmanyar, S.; Houk, K. N.; List, B. J. Am. Chem. Soc. 2003, 125, 16.

41. Rankin, K. N.; Gauld, J. W.; Boyd, R. J. J. Phys. Chem. A 2002, 106, 5155.

42. Arno, M.; Domingo, L. R. Theor. Chem. Acc. 2002, 108, 232.

43. Allemann, C.; Gordillo, R.; Clemente, F. R.; Cheong, P. H.; Houk, K. N. Acc. Chem. Res. 2004, 37, 558.

44. Bahmanyar, S.; Houk, K. N.; Martin, H. J.; List, B. J. Am. Chem. Soc. 2003, 125, 2475.

45. Zimmerman, H. E.; Traxler, D. M.. J. Am. Chem. Soc. 1957, 79, 1920.

46. Tanimori, S.; Naka, T.; Kirihata, M. Synth. Commun. 2004, 34, 4043.

47. Hammett constants were taken from Smith, M. B.; March, J. Advanced Organic Chemistry 5th Ed., John Wiley: New York, 2001, Table 9.4 on page 370. [ $\sigma_{\text {para }}-0.14(\mathrm{Me}), 0(\mathrm{H}), 0.24$ $\left.(\mathrm{Cl}), 0.81\left(\mathrm{NO}_{2}\right) ; \sigma_{\text {meta }}-0.06(\mathrm{Me}), 0(\mathrm{H}), 0.37(\mathrm{Cl}), 0.71\left(\mathrm{NO}_{2}\right)\right]$.

48. $\mathrm{N}$-(5-Chloro-2-hydroxyphenyl) (S)-pyrrolidine-2-carboxamide (9c) is air and light sensitive. It is not easy to obtain accurate specific rotation data. This data is just for reference. 